\title{
Prevalence of Community Deaths Positive for the Ebola Virus that Occurred in the City of Conakry \\ Mamadou Saliou Sow ${ }^{1}$, Mory Chérif Haïdara ${ }^{2}$, Diao Cissé ${ }^{3}$, Stanislas Djemo Djiro ${ }^{4}$, Boushad Mohamed Boushad ${ }^{5}$, N'Faly Magassouba ${ }^{2}$ \\ ${ }^{I}$ Département of Infectious Diseases, Donka National Hospital, Conakry, Guinea \\ ${ }^{2}$ Laboratory of Haemorrhagic fever, Guinea \\ ${ }^{3}$ Departement of Public Health, University of Conakry, Guinea \\ ${ }^{4}$ Medical Informatics Department, University of Conakry, Guinea \\ ${ }^{5}$ Department of Internal Medicine and Infectious Diseases, Kiffa Hospital, Assaba, Mauritania
}

Corresponding Author Diao Cissé

Mobile:

+224622370656

E mail:

diaosg49@gmail.com

Short title:

Community deaths

For the Ebola Virus

Key words: Ebola, Community Deaths, Conakry.
Context and objective: Ebola virus disease (EVD) is a contagious, serious, often fatal disease if left untreated, reaching a lethality rate of $90 \%$ during epidemics.

The objective of this study was to describe the Ebola positive community deaths that occurred in the city of Conakry during the Ebola Virus Disease (EVD) epidemic.

Patients and methods: This was a descriptive cross-sectional study conducted from 1 March to 31 August 2015, covering all positive community Ebola deaths in the city of Conakry that were recorded in the database of the National Ebola Control Coordination.

Results: During the study period, out of a total of 6589 community deaths recorded in Conakry city by National Ebola

\section{INTRODUCTION}

Ebola virus disease (EVD) is a contagious, serious, often fatal disease if left untreated, reaching a lethality rate of $90 \%$ during epidemics [1]. Since its appearance in 1976, about thirty epidemics have been reported, most of them with limited magnitude because they were restricted to remote forest areas in Central Africa [2].

The epidemic of EVD which lasted from December 2013 to March 2016 in West Africa, was of unprecedented magnitude and was one of the first to reach densely populated urban centres. On April 28, 2016, the date on which the end of the epidemic due to the EVD in Guinea was declared, the National Ebola Control Coordination (NECC) had identified 3814 cases (confirmed, probable and
Control Coordination, the proportion of Ebola positive death was $0.41 \%$. The average age was 38.77 years (extremes were 1 and 78 years). All age groups were affected, but the most affected was 31 to 40 years of age $(29.6 \%)$. The sex ratio was 0.58 . The municipality of Matoto recorded the highest rate of community Ebola virus positive deaths for during this period, $48 \%$ (13/27). The type of epidemiological link was mainly that related to health workers 303 (36.5\%).

Conclusion: This study shows a strong involvement of community deaths in the persistence of Ebola transmission chains. This is despite the efforts of the national and international community.

Improving the control of an Ebola epidemic in Guinea would require collaboration between communities and the epidemiological surveillance department.

suspect). Overall lethality was $66.7 \%$ (2544/3814), confirmed case lethality was $62.2 \%(2088 / 3,358)$ and case lethality in care centres was $50.6 \%$ $(1,300 / 2,570)$. A total of 788 positive Ebola deaths have been reported in the community by the NECC [3].

The spread of the virus in communities occurs through humanto-human transmission, through direct contact with blood, secretions from organs or body fluids of infected persons, or through indirect contact through environments contaminated with these types of fluids [4]. In Africa, funeral rites following community death are very favourable to the transmission of the virus among relatives and friends through close contact with the deceased and his or her personal belongings [5]. 
In Guinea, these funeral rites and traditional burials during community deaths are said to be responsible for $60 \%$ of the transmission of virus [6]. During epidemics of this magnitude, the application of strict health measures can interrupt the transmission chains of the virus. If these measures are applied, acute cases could become rare and contamination would only be caused by community deaths. Thus, the surveillance of these community deaths has a great importance in the management of an Ebola epidemic. As with all epidemiological surveillance, the surveillance of community deaths is based on the different functions: notification, identification, confirmation, investigation and response .
The objective of this study was to describe the Ebola positive community deaths that occurred in the city of Conakry during the Ebola Virus Disease (EVD) epidemic.

\section{PATIENTS AND METHODS}

\section{Study area}

Conakry is the capital of the Republic of Guinea. This administrative region includes 5 municipalities: Kaloum, Dixinn, Matam, Ratoma and Matoto (fig.1).

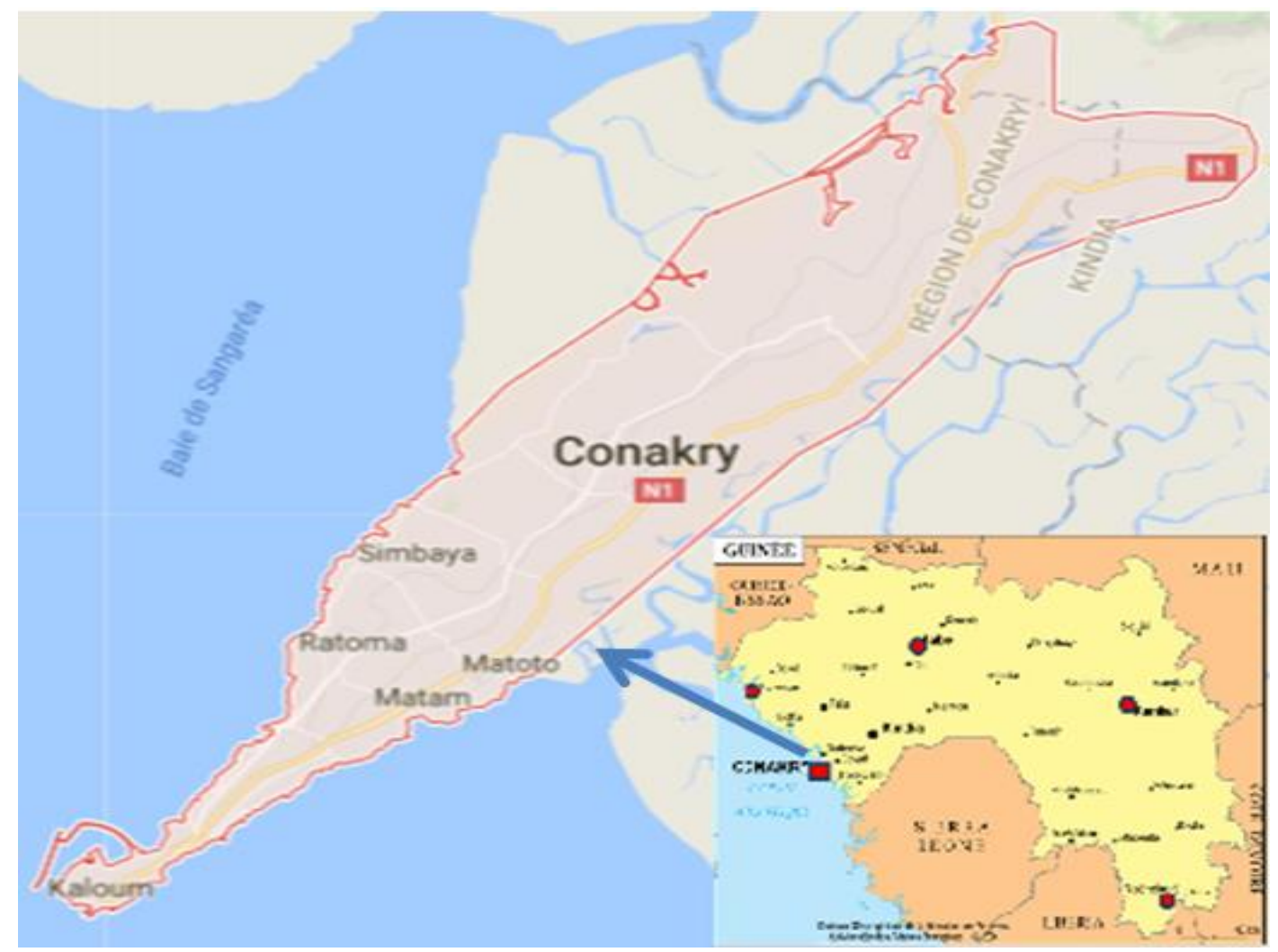

Figure 1: Cartography of the city of Conakry

\section{Type and period of study}

We conducted a descriptive cross-sectional study from March 1 to August 31, 2015.

\section{Study population}

The study covered all community deaths in Conakry that occurred in the city of Conakry and were recorded in the database of the NECC.

\section{Inclusion criteria}

All Ebola positive community deaths in the city of Conakry listed in the NECC database were included.

\section{Exclusion criteria}

All negative community deaths due to the virus in the city of Conakry were excluded. 


\section{Data collection tools and techniques}

\section{Data collection procedure}

During this study period, an oral sample was taken from all community deaths for RT-PCR to detect Ebola positive community deaths. In the event of a positive death, a secure burial was carried out by the RC and an investigation was opened to find contacts .

Community death: has been defined as any death occurring outside Ebola Treatment Centres (ETCs) [7].

All suspected cases benefited from a blood sample for the detection of the viral genome by reverse transcription polymerase chain reaction (RT-PCR) and MVE serology at the haemorrhagic fever laboratory in Conakry [1]. For any suspected case identified and whose domicile could be found, an active search for the case was carried out in its place of residence. If the suspected case was present at the time of the investigation, an inclusion in the investigation was proposed to him and to members of his entourage. If the suspected case was absent or deceased, the inclusion was proposed to the members of his entourage. A search for suspected or probable cases in the community was systematically carried out by interviewing those present.

A suspicious case: Any living person who has been in contact with a confirmed or probable case and has had a high fever $\left(\geq 38^{\circ} \mathrm{C}\right)$ of sudden onset or at least three of the following symptoms: headache, anorexia/loss of appetite, lethargy; muscle or joint pain, breathing difficulties, vomiting, diarrhoea, stomach-ache, swallowing difficulties, hiccups, unexplained bleeding; or unexplained community death؛

Community alert case: Anyone with a sudden onset of high fever that does not respond to any treatment of the common causes of fever in the area; or anyone who has experienced bleeding, bloody diarrhoea or haematuria; or anyone who dies suddenly.

Probable case: any person who died without being sampled with a proven epidemiological link to a confirmed case or other probable case; or a subject from a community where the epidemic has been active for less than 21 days and for whom response personnel have reasonable grounds to suspect the EVD.
Confirmed case: Any suspected or probable case with a positive laboratory result. They must be positive for either virus antigen, viral RNA detected by reverse transcription followed by polymerase chain reaction (RT-PCR) or IgM antibodies to Ebola.

Non-case: Any suspicious or probable case with a negative laboratory result. The "non-cases" were free of specific antibodies, RNAs and detectable specific antigens.

Ebola case contact person: Any person who has been in contact with an Ebola or Marburg case within 21 days before the onset of symptoms in at least one of the following ways :

- slept in the same household as the case

- had direct physical contact with the case (living or deceased) during his illness

- had direct physical contact with the case (deceased) during the funeral

- had direct contact with the case's blood or body fluids during his or her illness

- had direct contact with the patient's clothing or linen - was breastfed in one case (for a baby).

Each contact was identified and followed for 21 days. Contacts that became suspicious (appearance of the first signs or symptoms) were transferred to the Ebola Treatment Centre (ETC) for sampling.

\section{Data Analysis}

Data were exported from the Epi-Info software (MS-Access 97) to an MS-Excel 2003 format and then analyzed using the SPSS 20 software.

\section{RESULTS}

A total of 6589 deaths were recorded in the city of Conakry during our study period, of which $0.41 \%$ (27/6589) were tested positive for the EV. The average age of those who died with a positive Ebola laboratory result was 38.77 years (extreme: $1-78$ years) and the sex ratio was 0.58 (M/F). 48\% (13/27) of these community deaths positive for EV occurred in the commune of Matoto (Table 1). The total number of contacts recorded around these 27 deaths was 831, broken down as follows, depending on the type of epidemiological link: $38.6 \%$ (303/831) were health workers, $28.6 \%$ (238/831) were relatives 
from different families, $28.0 \%$ (233/831) were related to the community (neighbours, friends, etc.) and $6.9 \%(51 / 831)$ were from unknown sources. The seroprevalence of EV among the contacts was $2.05 \%$ (17/831).

The distribution curve of Ebola positive community deaths was divided into three (3) phases (Figure 2):

- Phase 1: started at week 9 and ended at week 10. The curve increases to a peak at week 10.

During this phase, the number of weekly deaths increases from 4 to 6 .

Table 1: Distribution of the 27 Ebola positive community deaths in Conakry in March-August 2015 by socio-demographic characteristics.

\begin{tabular}{|c|c|c|c|}
\hline \multicolumn{2}{|c|}{ Socio-demographic characteristics } & Number & $(\%)$ \\
\hline \multirow[t]{2}{*}{ Sex } & Female & 17 & 62,96 \\
\hline & Male & 10 & 37,04 \\
\hline Average age & & $(38,7 \pm 11,3)$ & \\
\hline \multirow[t]{2}{*}{ Marital status } & Maried & 343 & 59,9 \\
\hline & Single & 230 & $40,1 \%$ \\
\hline \multirow[t]{5}{*}{ Municipality } & Matoto & 13 & 48,14 \\
\hline & Ratoma & 6 & 22,22 \\
\hline & Matam & 4 & 14,81 \\
\hline & Dixinn & 2 & 7,40 \\
\hline & Kaloum & 2 & 7,40 \\
\hline \multirow[t]{5}{*}{ Age groups } & $0-20$ & 16 & 59,3 \\
\hline & $21-40$ & 4 & 14,8 \\
\hline & $41-60$ & 1 & 3,7 \\
\hline & $61-80$ & 4 & 14,8 \\
\hline & Plus de 81 & 2 & 7,4 \\
\hline \multirow[t]{4}{*}{ Type of contact } & Health care worker & 303 & 36,5 \\
\hline & Relatives & 238 & 28,6 \\
\hline & Communauty & 233 & 28,0 \\
\hline & Unknown & 57 & 6,9 \\
\hline Positive deaths & $\mathrm{n}(\%)$ & 17 & $2,05 \%$ \\
\hline
\end{tabular}




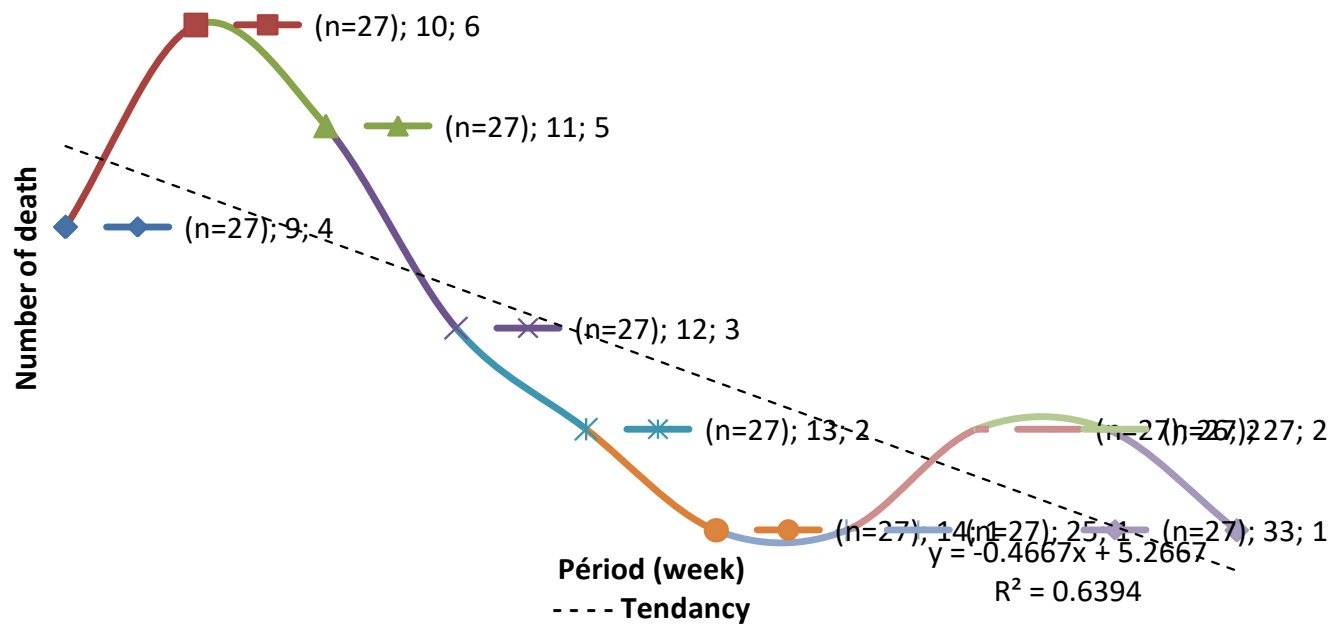

Figure 2: Evolution of the distribution curve of the 27 Ebola positive community deaths in Conakry according to the weeks of notification from March to August 2015.

\section{DISCUSSION}

Our study aimed to describe community deaths that were positive for EV, encountered difficulties, including the lack of completeness in the database provided to us by the NECC. The systematic use of RT-PCR on all oral samples from community deaths in the areas affected by this epidemic has led to the detection of Ebola positive deaths. Thus, out of a total of 6589 community deaths recorded by the NECC during the study period, $0.41 \%(27 / 6589)$ tested positive for the EV.

This low proportion of positive community Ebola deaths in the city of Conakry has a significant implication that is reflected in the persistence of Ebola transmission chains. Many hidden patients were not identified or confirmed until after their death, and a few were probably never identified or confirmed. This was the result of the deep reluctance of part of the population who preferred to hide the sick and dead patients of Ebola and also testified to the difficulties and inadequacies of community communication of the response. These hidden patients and deaths positive for EV have contributed significantly to the persistence of virus transmission to families, friends and neighbours through their exposure to the virus during the illness phase and after death during funeral rites [3].

A female predominance emerged from this study with $63 \%(17 / 27)$ and a sex ratio of 0.58 . This result is consistent with national epidemiological surveillance data reported by Migliani et al. [6] with $52.7 \%$ female. These women were probably the most exposed during patient care and funeral rites.. This is a common practice in traditional African societies .

In contrast, in Ogooué Ivindo province, located in north eastern Gabon, during the EVD outbreak of October 2001- April 2002, Nkoghe et al. [8] regained male dominance with 34 cases $(52 \%)$. This difference could be explained by the circumstances of contamination in the community. In this province, transmission was zoonotic with several indexed cases, mostly hunters in rural areas. In Conakry, on the other hand, was essentially a human-to-human transmission during the care of the sick and funeral rites undertaken by members of the family and community of the sick.

The average age found in our study was 38.77 years with extremes of 1 year and 78 years. The age groups 31 to 40 years old $(29.6 \%)$ and 51 and over $(29.6 \%)$ were the most represented. In Guinea, for all deaths combined (deaths in ETCs and community deaths) related to EVD, all age groups were affected in the same proportions [3].

In our study, people who were between 31 to 40 years old and those who were 51 years and more were the most affected. This could be explained by the fact that in Guinea, people aged 31 to 40 represent an active part of the population [9]. 
These people could be in charge of transporting the bodies during funeral rites in the community. The age group of 51 years and over represents middle-aged people. They are very exposed during the practice of funeral rites because they are the ones who take part in the washing of the bodies.

During our study, the municipality of Matoto was the one that recorded the highest percentage of community deaths positive for Ebola virus with 13 cases (48.1\%). This could be due to the high population density in this municipality. Indeed, according to data from the third general population and housing census of 2014 (RGPH/3/2014), the municipality of Matoto is the most populated with 666,640 inhabitants.

The 27 community deaths that were positive for EV during our study had 831 contacts. Among these contacts, health workers were the most represented at $36.5 \%$ (303/831). This result could be explained by the fact that health workers have been on the front line. They have paid a heavy price for this epidemic, especially doctors and nurses who have been more at risk than the rest of the population. Health workers were followed in hospital for 21 days. If suspicious signs of EVD appeared, they were transferred to the ETC for confirmation and possibly for management. Also, 28.6\% (238/831) contacts were identified within the families of victims compared to $28.0 \%$ (233/831) contacts in the community. This result may not reflect reality given the reluctance of investigative teams in these environments.

In addition, $2.05 \%$ (17/831) contacts were tested positive for EV. This reflects the involvement of positive community deaths in the persistence of virus transmission chains. Indeed, in African communities, traditional mortuary rituals practiced at the time of a community death are highly respected, including mortuary cleansing. However, these funeral rites favour the transmission of the virus to relatives and friends through close contact with the deceased and his or her personal belongings [10].

The analysis of the weeks of notification shows that during the first phase, the difficulties related to the taking of community deaths and the organisation of secure burials were not all resolved. As the provisions became more widespread and Red Cross (RC) teams became operational, the number of community deaths that were positive for Ebola decreased.

\section{CONCLUSSION}

This study shows a strong involvement of community deaths in the persistence of Ebola transmission chains. This is despite the efforts of the national and international community.

Improving the control of an Ebola epidemic in Guinea would require collaboration between communities and the epidemiological surveillance department.

Ethical approval:Approved.

\section{Funding:None.}

\section{Conflict of interest: None.}

\section{REFERENCES}

1. Vailaya CGR, Kumar S, Moideen S. Ebola Virus Disease: Practices Health Care Professionals in a Tertiary Care Hospital Knowledge, Attitude, of. J Pub Health Med Res. 2014;2:13-8 .

2. Rapp C. Epidémie à virus Ebola en Afrique de l'Ouest: réalités et perspectives. Médecine Santé Trop. 2014;24:229-31 .

3. Migliani R, Keïta S, Diallo B, Mesfin S, Perea W, Rodier G. Aspects épidémiologiques de la maladie à virus Ebola en Guinée (décembre 2013-avril 2016). Société Pathol. Exot. Lavoisier. 2016;44:149-60 .

4. Formenty P, Epelboin A, Allarangar Y, Allarangar F, Boumandouki P, Koné L, et al. Séminaire de formation des formateurs et d'analyse des épidémies de fièvre hémorragique due au virus Ebola en Afrique centrale de 2001 à 2004. Bull Soc Pathol Exot. 2005;98:244-54 .

5. Migliani R, Keita S, Diallo B, Rodier G, Perea W, Dahl B. Maladie à virus Ebola en Guinée : évolution de l'épidémie de son émergence en décembre 2013 à novembre 2015. Médecine Armée. 2016;44:149-60 .

6. .oucaud O. Ebola: le prix à payer d'un fiasco à tous les étages. Lett. Infect. 2014;XXIV:160-2 .

7. Organisation Mondiale de la Santé (OMSAfrique). Définition de cas recommandées pour la surveillance des maladies à virus Ebola et Marburg [Internet]. 2016 [cited 2016 Aug 2]. Available from: http://www.who.int/csr/disease/ebola/Ebola_Defi nition_de_Cas_Contacts.pdf

8. Nkoghe D, Formenty P, Leroy EM, Nnegue S, Obame Edou SY, Iba Ba J, et al. Plusieurs épidémies de fièvre hémorragique due au virus Ebola au Gabon, octobre 2001 à avril 2002 . 
9. Institut National de la Statistique Ministère du Plan/Guinée, Measure DHS/USA, ICF International/USA. Enquête démographique et de Santé et á Indicateurs Multiples (EDS-MICS) 2012. 2013.
10. Boumandouki P, Formenty P, Epelboin A, Campbell P, Atsangandoko C, Allarangar Y, et al. Prise en charge des malades et des défunts lors de l'épidémie de fièvre hémorragique due au virus Ebola d'octobre à décembre 2003 au Congo. Bull Soc Pathol Exot. 2003;98:218-23. 